\title{
Cambios en el rol de la mujer en los diversos contextos de los sistemas productivos campesinos en el departamento de Boyacá, Colombia
}

\section{Woman's role changes in different contexts of productive peasant systems in Boyacá department, Colombia}

\author{
As mudanças no papel das mulheres nos diversos contextos \\ de sistemas de produção caipira em Boyacá, Colombia
}

\begin{abstract}
Diana Milena Soler Fonseca ${ }^{1}$, Jorge Armando Fonseca Carreño² \& Randy Alexis Jiménez Jiménez ${ }^{3}$
${ }^{1}$ Médico Veterinario Zootecnista, Especialista en Nutrición Animal Sostenible, Magister en Desarrollo Rural, ²Ingeniero Agrónomo. Especialista en Finanzas. Especialista en Evaluación Pedagógica. Magister en Ciencias Agrarias. Estudiante Doctorado en Agroecología de la Universidad Nacional de Colombia. Sede Bogotá. ${ }^{3}$ Médico Veterinario Zootecnista, Magister en Ciencias de la Producción y la Salud Animal, Estudiante Doctorado en Desarrollo Rural de la Universidad Autónoma Metropolitana de México.

1, 2Escuela de Ciencias Agrícolas,Pecuarias y del Medio Ambiente -ECAPMA. Universidad Nacional Abierta y a Distancia -UNAD. Tunja. Boyacá. Colombia. ${ }^{3}$ Departamento de Economía, Administración y Desarrollo Rural. Facultad de Medicina Veterinaria y Zootecnia. Universidad Nacional Autónoma de México. Av. Universidad \#3000 Circuito Exterior, Ciudad Universitaria. Coyoacán Código Postal 04510, México D.F.
\end{abstract}

11diana.soler@unad.edu.co, 2jorge.fonseca@unad.edu.co, ${ }^{3}$ alexis.j2@gmail.com

\section{Resumen}

En el medio rural del departamento de Boyacá (Colombia) los integrantes de la familia campesina han venido transformando sus roles, haciéndose más visible la participación de las mujeres en las actividades productivas y en la toma de decisiones relacionadas con las mismas. Esta investigación hace un diagnóstico de las familias estudiadas con el objetivo de detectar y analizar los posibles cambios en el rol de la mujer campesina dentro de los sistemas productivos. Se utilizó una metodología cualitativa involucrando 10 familias campesinas de Duitama y 30, de Paipa. Los resultados mostraron que la mujer sigue realizando las tareas que demandan mayor esfuerzo y tiempo dentro del hogar, ha tenido que liderar los sistemas agrícolas pequeños y medianos y participa de forma activa en la comercialización de los productos agrícolas, permitiéndole el control y manejo parcial de los dichos ingresos monetarios. En el ámbito pecuario las mujeres juegan un papel fundamental en el manejo de los animales y la comercialización de sus productos, controlando en una alta proporción los ingresos monetarios de estos sistemas. Además, las mujeres realizan labores extraprediales y buscan otros lugares para vender mejor sus productos y obtener más ingresos económicos que ayuden al sostenimiento de sus familias. Se concluye que aunque las mujeres tienen más control sobre los recursos y producciones de sus predios, estos cambios en sus roles han significado una sobrecarga laboral, que sigue invisibilizada por las leyes y/o programas del gobierno, en general.

Palabras clave: productivo, reproductivo, acceso, control, decisiones, mujer 


\section{Abstract}

Peasant family members in Boyacá (Colombia) department's rural zone haven been transforming their roles, making women's involvement in productive activities and decision-making more visible. In this research, a diagnostic is made about the studied families with the objective of detecting and analyzing the possible changes of peasant woman's role in productive systems. A quantitative methodology was used, involving 10 peasant families from Duitama and 30, from Paipa. The results showed that woman continue to do physically demanding domestic tasks, in addition to being responsible for small and medium-sized agricultural operations and their active participation in the commercialization of agricultural products, thus giving women control and partial management of income from said operations. Regarding livestock management, women play a fundamental role in animal care and the commercialization of products, controlling a high proportion of the income coming from these sources. Furthermore, women complete other agricultural tasks and look for better places to sell their products and to obtain additional income that help support their families. It was concluded that despite having more control over economic resources and the products of their properties, these changes in roles have meant a work overload that continues to go unrecognized by laws and/or government projects, in general.

Key-words: productive, reproductive, access, control, decisions, woman.

\section{Resumo}

Nas áreas rurais do Departamento de Boyacá (Colombia) membros da família caipira têm vindo a transformar seus papéis, tornando-se mais visível a participação das mulheres nas atividades produtivas e na tomada de decisões relacionadas com elas. Este estudo faz um diagnóstico das famílias estudadas com o objetivo de identificar e analisar possiveis mudanças no papel das mulheres rurais em sistemas produtivos. A metodologia utilizada foi qualitativa, envolvendo 10 famílias caipira de Duitama e 30 de Paipa. Os resultados mostraram que as mulheres continuam a realização de tarefas que exigem mais esforço e tempo em casa, tem tido que levar os pequenos e medianos sistemas agrícolas e participa ativamente na comercialização de produtos agrícolas, permitindo o controle parcial e gestão a renda monetária disse. Na área de pecuária mulheres desempenham um papel fundamental no manejo animal e comercialização dos seus produtos em uma alta proporção controlando em grande proporção as entradas monetárias desses sistemas. Além disso, as mulheres procuram trabalho fora da agricultura e em outros lugares para vender seus produtos melhor e mais renda para ajudar a sustentar suas famílias. Conclui-se que, embora as mulheres tenham mais controle sobre os recursos e as produções de suas propriedades, essas mudanças em seus papéis significaria uma sobrecarga de trabalho, que permanece invisivel por lei e / ou programas de governo em geral.

Palavras-chave: produtivo, reprodutivo, acesso, controle, decisões, mulher

\section{Introducción}

En Colombia la mayor parte de los campesinos son productores familiares agropecuarios, sus unidades de producción son al mismo tiempo unidades de consumo cuya finalidad es la reproducción de la familia o la comunidad, imprimiéndole el carácter organizativo a la actividad productiva. La producción está organizada de acuerdo al sistema de decisiones de la familia o de la comunidad, la división de tareas entre sus miembros está dada de acuerdo a la edad, sexo, jerarquías, experiencias y conocimientos adquiridos (Forero et al., 2003).

En este sentido, dentro de estas producciones familiares la mujer y el hombre jefe de hogar son responsables de la sostenibilidad de sus unidades 
campesinas ya que deben repartirse actividades y compartir roles; es por esto que cuando se estudian los sistemas productivos campesinos, el aspecto de género es de vital importancia, entendido éste como "una construcción social del ser hombre y ser mujer, del ser femenino y del ser masculino, que partiendo de las características biológicas, pero trascendiéndolas, le da a las mujeres diferentes poderes y roles frente a los hombres; y al mismo tiempo, permite y condiciona las relaciones entre hombres y mujeres, entre lo masculino y lo femenino en una sociedad" (Farah, 1996).

De acuerdo con lo anterior, en el medio rural la mujer y el hombre han venido transformando sus roles, haciéndose más visible la participación de las mujeres en las actividades productivas y en la toma de decisiones relacionadas con las mismas. Es así como se ha constatado la estrecha relación que existe entre mujeres y el medio rural, las mujeres producen la mitad de los alimentos producidos en el mundo, y son las encargadas en muchos países de manejar las fincas, acarrear la leña y el agua y criar los animales (en tanto los hombres, compañeros y niños mayores, trabajan en fincas comerciales y centros urbanos) (BID, 1997ª , citado en IICA, 2000 p. 30).

Adicionalmente, vale la pena citar que desde los años ochenta la fuerza laboral del sector rural se ha reducido (de 32.4 a 28.8 millones entre 1980 hasta 1994), sin embargo, la proporción femenina ha aumentado (de 34 a 44 millones en el mismo periodo). El progresivo aporte de las mujeres al ingreso familiar permite mantener fuera de la pobreza (o disminuir sus efectos) a un creciente contingente de los hogares rurales de la región. (BID, 1997a, citado en IICA, 2000 p. 31).

En el mundo en desarrollo a pesar de que las mujeres rurales trabajan hasta 16 horas al día, realizando labores domésticas, agrícolas y de otra índole (producen, elaboran, comercializan y preparan alimentos, cuidan hijos, entre otras), la mayoría no recibe remuneración directa por su trabajo. Las mujeres rurales están sobre empleadas en cuanto al número de horas trabajadas, y subempleadas en cuanto a los ingresos percibidos (BID, 1997c, citado en IICA, 2000 p. 31).

Colombia y específicamente el departamento de Boyacá no ha sido ajena a esta situación, ya que, al ser un departamento altamente agropecuario, contiene gran cantidad de unidades campesinas, las cuales presentan algún tipo de homogeneidad en sus sistemas productivos y distribución de las labores entre hombres y mujeres.

Aunque en este departamento se han realizado varios estudios de género enfocados hacia el análisis y evaluación de políticas públicas, seguridad alimentaria, violencia, participación femenina en general y aspectos socioculturales en municipios como Motavita (Rodríguez, 1988), Puerto Boyacá (Forero, 2003), Oicatá (Garzón et al., 2007), Tenza (Avella et al., 2007), Socotá (Vera 1999), Sogamoso (Torres, 2004), y zonas como el occidente de Boyacá (Buitrago, 1990), no han sido suficientes para reflejar verdaderamente los cambios en el rol de la mujer dentro de los sistemas productivos y más en el sector rural.

Lo anterior indica que en el departamento de Boyacá se deben generar más estudios de género que propendan por exteriorizar las realidades de la mujer rural, y los cambios que las mismas han debido hacer para adaptarse a la nueva ruralidad tan cambiante en los últimos años. El presente artículo busca profundizar un poco más sobre el tema de la mujer en los sistemas productivos campesinos, sus roles y los cambios que los mismos han sufrido debido a las transformaciones del campo en general en los municipios de Duitama (vereda la Pradera) y Paipa (veredas Medios, Jazminal y Salitre Alto) del departamento de Boyacá.

\section{Materiales y métodos}

En esta investigación se utilizó la metodología cualitativa, la cual intenta hacer una aproximación global a las situaciones sociales para explorarlas, 
describirlas y comprenderlas de manera inductiva, permitiendo un acercamiento a las familias estudiadas y al quehacer diario de sus integrantes.

Para esta investigación realizada en el año 2012, se eligieron 10 familias del municipio de Duitama (vereda la Pradera) y 30 del municipio de Paipa (veredas Medios, Jazminal y Salitre Alto) las cuales debían contar con las siguientes condiciones: vivir en predios rurales, tener producciones agrícolas y pecuarias dentro de los mismos, estar dispuesto a brindar información pertinente para esta investigación. Las herramientas utilizadas para recolectar la información fueron encuestas semiestructuradas, diálogos con los familiares (mayormente mujeres) y observaciones en los predios y las actividades desarrolladas dentro de los sistemas de producción, las cuales se elaboraron teniendo en cuenta el objetivo de esta investigación y preguntas de tipo abiertas y cerradas que conllevaran a la recolección de experiencias, perspectivas, comportamientos, entre otros, propios de las familias a estudiar.

Esta investigación tuvo como objetivo principal realizar un diagnóstico de las familias estudiadas para luego detectar y analizar los posibles cambios en el rol de la mujer campesina dentro de los sistemas productivos.

Una vez obtenida la información de las diversas familias se procedió a sistematizarla con el método de lista de conteo para favorecer la comprensión y análisis de los datos recogidos. Por último, se realizó la triangulación, análisis y conclusiones que se presentan en este artículo.

\section{Resultados}

\section{Rol de la mujer en el ámbito reproductivo}

Las mujeres siempre han tenido el rol reproductivo a lo largo de su existencia; en este contexto, las labores del hogar se van transmitiendo a otras mujeres que hacen parte de la familia (hijas, nietas, nueras, sobrinas, entre otras) haciendo que estas actividades sean compartidas y/o distribuidas entre las mismas. En este sentido, se podría creer que aquellas familias que tengan más miembros femeninos dentro de su núcleo familiar pueden ayudar en las labores reproductivas y contrarrestar su tiempo de dedicación.

Lo anterior se puede apreciar en las familias estudiadas del municipio de Paipa y Duitama, dentro de las cuales las mujeres representan el $55 \%$ y $52,9 \%$ respectivamente y los hombres el $45 \%$, y $47 \%$ (Figura 1); sin embargo, estos datos toman real importancia al observar las edades de estos grupos de género y conocer qué rol desempeñan dentro de sus predios.

(A)

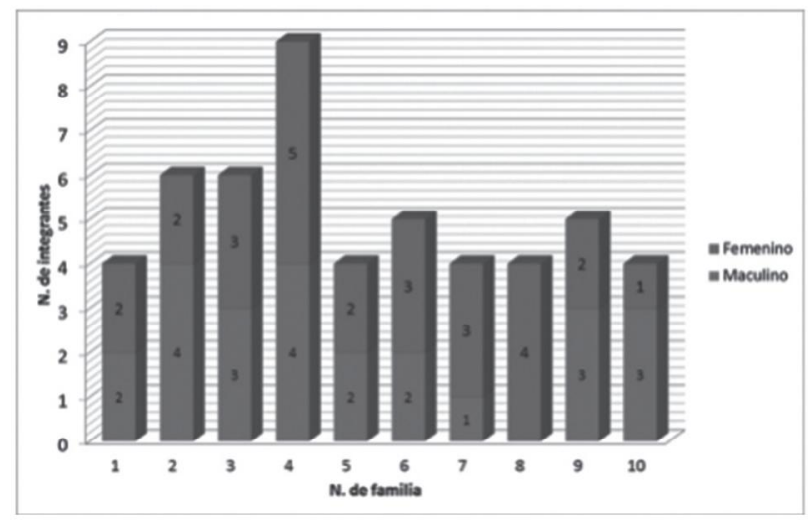

(B)

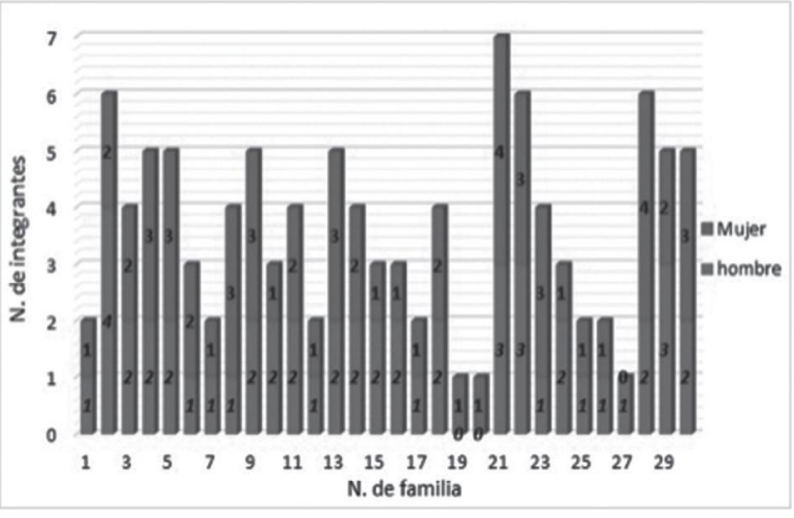

Figura 1. Composición por número y sexo de las familias estudiadas de los municipios de Paipa (A) y Duitama (B) 
De acuerdo con lo observado en los municipios de Paipa y Duitama, los adultos comprendidos entre 30 y 69 años son los que más persisten en los predios $(58.7 \%$ y $37.2 \%$ respectivamente) seguidos de los jóvenes y adolescentes entre 13 y 29 años (24.76\% y $35.2 \%$ respectivamente, esto indica que la mayoría de las mujeres que se encuentran en los predios son adultas y por ello desempeñan mayormente las labores del hogar.

Sin duda, las jóvenes y adolescentes ayudan en las labores del hogar ya que luego de su jornada académica realizan dichas actividades (barren la casa, tienen las camas, lavan de vez en cuando la loza y su propia ropa, entre otras labores sencillas) y descansan a la madre de algunas de estas prácticas (ver Tabla 1). Sin embargo, aunque pa- reciera que lo anterior disminuye la cantidad de actividades reproductivas que una mujer debe desarrollar en su día a día, al contrario duplica sus labores ya que se ven forzadas a desplazar sus actividades reproductivas por las productivas las cuales se describirán más adelante.

Un aspecto a resaltar es la intervención de los niños y jóvenes del género masculinos dentro del ámbito reproductivo, ya que estos están siendo concientizados por sus madres para colaborar en todos los oficios de la casa luego de sus jornadas académicas, igualando las responsabilidades dentro del hogar y descargándose de estos quehaceres (arreglo de la ropa, aseo del hogar, lavar la loza, tendida de camas, mandados, etc.) lo anterior se evidenció en el $60 \%$ de las familias estudiadas.

Tabla 1. Distribución de las labores reproductivas dentro del predio de las 10 familias más representativas

\begin{tabular}{|c|c|c|c|c|c|c|c|c|c|c|}
\hline \multicolumn{11}{|c|}{ SISTEMA REPRODUCTIVO } \\
\hline ACTIVIDAD & Familia 1 & Familia 2 & Familia 3 & Familia 4 & Familia 5 & Familia 6 & Familia 7 & Familia 8 & Familia 9 & Familia 10 \\
\hline Aseo del hogar & Hija & $\begin{array}{l}\text { Madre, } \\
\text { Hija }\end{array}$ & $\begin{array}{l}\text { Madre, } \\
\text { Hija }\end{array}$ & $\begin{array}{l}\text { Madre, } \\
\text { Hija }\end{array}$ & $\begin{array}{l}\text { Madre, } \\
\text { Padre }\end{array}$ & $\begin{array}{l}\text { Madre, } \\
\text { Hija, hijo }\end{array}$ & $\begin{array}{l}\text { Madre, } \\
\text { Padre }\end{array}$ & $\mathrm{Hija}$ & $\begin{array}{l}\text { Madre, } \\
\text { Hija }\end{array}$ & $\begin{array}{l}\text { Madre, } \\
\text { Hijo }\end{array}$ \\
\hline $\begin{array}{l}\text { Compra } \\
\text { artículos hogar }\end{array}$ & Hija & Madre & $\begin{array}{l}\text { Madre, } \\
\text { Padre }\end{array}$ & Padre & $\begin{array}{l}\text { Madre, } \\
\text { Padre }\end{array}$ & $\begin{array}{l}\text { Madre, } \\
\text { Padre }\end{array}$ & $\begin{array}{l}\text { Madre, } \\
\text { Padre }\end{array}$ & $\begin{array}{l}\text { Madre, } \\
\text { Hija }\end{array}$ & $\begin{array}{l}\text { Madre, } \\
\text { Hija }\end{array}$ & $\begin{array}{l}\text { Padre, } \\
\text { Abuelo }\end{array}$ \\
\hline $\begin{array}{l}\text { Compra } \\
\text { alimentos }\end{array}$ & Hija & $\begin{array}{l}\text { Madre, } \\
\text { Hija }\end{array}$ & Madre & Padre & $\begin{array}{l}\text { Madre, } \\
\text { Padre }\end{array}$ & $\begin{array}{l}\text { Madre, } \\
\text { Padre }\end{array}$ & $\begin{array}{l}\text { Madre, } \\
\text { Padre }\end{array}$ & $\begin{array}{l}\text { Madre, } \\
\text { Hija }\end{array}$ & $\begin{array}{c}\text { Madre, } \\
\text { Hija }\end{array}$ & $\begin{array}{l}\text { Padre, } \\
\text { Abuelo }\end{array}$ \\
\hline $\begin{array}{l}\text { Preparación } \\
\text { alimentos }\end{array}$ & Madre & $\begin{array}{l}\text { Madre, } \\
\text { Hija }\end{array}$ & $\begin{array}{l}\text { Madre, } \\
\text { Hija }\end{array}$ & Madre & Madre & $\begin{array}{l}\text { Madre, } \\
\text { Padre }\end{array}$ & Madre & $\begin{array}{l}\text { Madre, } \\
\text { Hija }\end{array}$ & $\begin{array}{l}\text { Madre, } \\
\text { Hija }\end{array}$ & Madre \\
\hline $\begin{array}{l}\text { Arreglo } \\
\text { Ropa }\end{array}$ & Familia & $\begin{array}{l}\text { Madre, } \\
\text { Hija, Hijo }\end{array}$ & Madre & Hija & Madre & Madre & Madre & $\begin{array}{l}\text { Madre, } \\
\text { Hija }\end{array}$ & $\begin{array}{l}\text { Madre, } \\
\text { Hija }\end{array}$ & N/A \\
\hline $\begin{array}{l}\text { Cuidado niños, } \\
\text { ancianos }\end{array}$ & Hija & N/A & Madre & Padre & Madre & $\begin{array}{l}\text { Madre, } \\
\text { Padre }\end{array}$ & Madre & Hija & $\begin{array}{c}\text { Madre, } \\
\text { Hija }\end{array}$ & N/A \\
\hline $\begin{array}{l}\text { Educación, } \\
\text { tareas }\end{array}$ & Hija & N/A & Madre & Familia & $\begin{array}{l}\text { Madre, } \\
\text { Padre }\end{array}$ & Madre & $\begin{array}{l}\text { Madre, } \\
\text { Padre }\end{array}$ & $\mathrm{Hija}$ & $\begin{array}{l}\text { Madre, } \\
\text { Hija }\end{array}$ & $\begin{array}{c}\text { Madre, } \\
\text { Hijo }\end{array}$ \\
\hline Reuniones & $\mathrm{Hija}$ & Madre & Madre & Padre & $\begin{array}{l}\text { Madre, } \\
\text { Padre }\end{array}$ & Madre & $\begin{array}{l}\text { Madre, } \\
\text { Padre }\end{array}$ & $\mathrm{Hija}$ & $\begin{array}{c}\text { Madre, } \\
\text { Hija }\end{array}$ & $\begin{array}{l}\text { Madre, } \\
\text { Padre }\end{array}$ \\
\hline
\end{tabular}

N/A: actividad no existente en la familia

Convención: $\square$ Intervención Femenina. $\square$ Intervención Masculina. $\square$ Intervención mixta 
Por otra parte, cuando se investigó sobre las actividades principales y secundarias que realizan las mujeres de las familias implicadas, se pudo observar que aparte de su actividad principal de amas de casa y actividades reproductivas (tanto para adultas como para jóvenes) tienen varias actividades secundarias, que no están relacionadas con el contexto productivo de sus predios.

En este sentido, el $20 \%$ de las familias estudiadas del municipio de Paipa ha establecido en sus hogares pequeños negocios de distribución (tiendas) las cuales son atendidas por las mujeres; el $50 \%$ de las familias estudiadas del municipio de Duitama tienen mujeres que venden artículos por catálogo (cosméticos y ropa de reconocidas marcas a nivel nacional) y el 10 y $40 \%$ de las mujeres entrevistadas tejen y atienden labores en otros predios (lavar ropa, ordeñar, entre otros) respectivamente.

Es importante destacar que las labores secundarias (venta de artículos por catálogo, ayudar en la tienda familiar, jornales fuera del predio, entre otros), no solo las realizan los padres y madres sino también los hijos (estudiantes o no) que conviven en el mismo hogar, con el fin de obtener más ingresos económicos y ayudar al sostenimiento de la familia, ya que las mujeres que más actividades secundarias tienen son las que viven en los predios más pequeños, y/o tienen ausencia del padre o pocos miembros masculinos dentro del hogar (menos ingresos en la familia).

\section{Rol de la mujer en el sistema agrícola y pecuario}

El rol de las mujeres en los sistemas agrícolas y pecuarios se ve influenciado por factores como el tamaño del predio, presencia del padre como cabeza de hogar o género masculino dentro de la familia y tipos de producciones agrícolas y pecuarias desarrolladas.

Ante lo anterior, los predios que predominan en las familias encuestadas son microfundios, (igual o menos de 2.5 hectáreas de acuerdo con el plan de desarrollo de Duitama (2008) y la oficina de planeación del municipio de Paipa (2010)), representados por un $70 \%$, seguidos de los latifundios representados por un $16.7 \%$ y finalmente, los minifundios representados por un $13.3 \%$, como se observa en las figura 2.

(A)

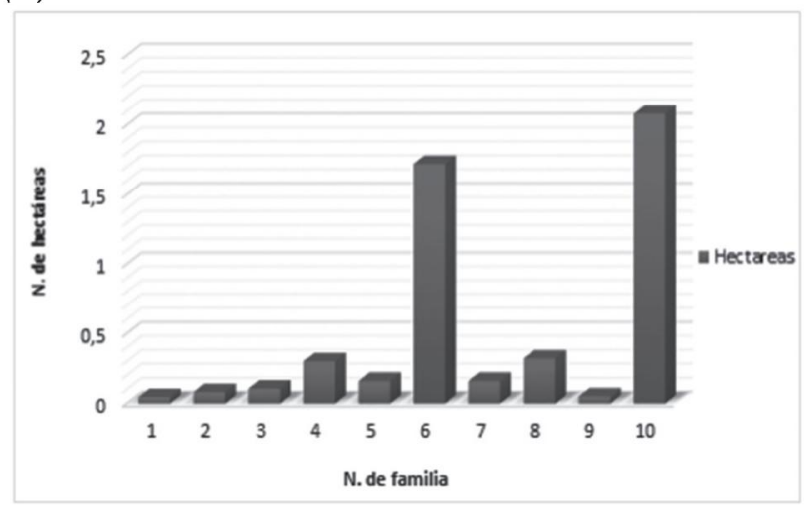

(B)

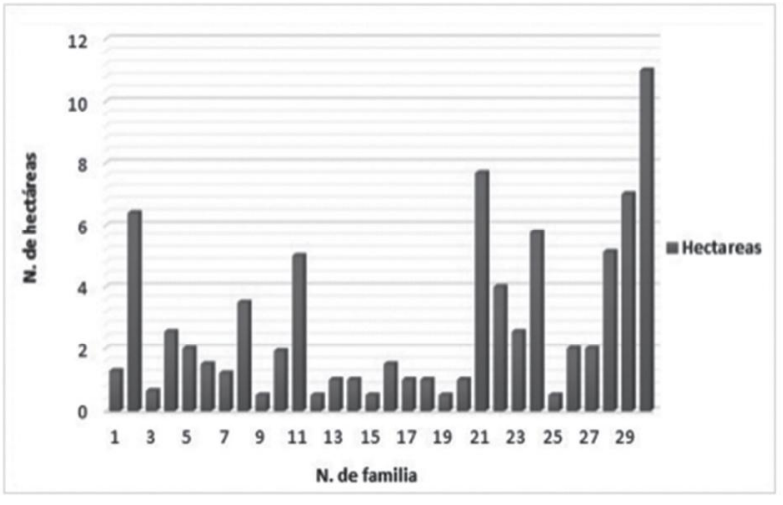

Figura 2. Tamaño de los predios de las familias estudiadas de los municipios de Paipa (A) y Duitama (B).

De acuerdo al tamaño de los predios, las familias campesinas encuestadas presentan producciones agrícolas y pecuarias pequeñas con el objetivo de proporcionar alimento a sus familias (autoabastecimiento) y vender en algunos casos, los excedentes de producción (papa, maíz, frutales, cilantro, papayuela, entre otros); los productos agrícolas que más se cultivan se muestran en la Figura 3, los cuales son destinados en su mayoría al autoconsumo y en menor cantidad a la venta. 


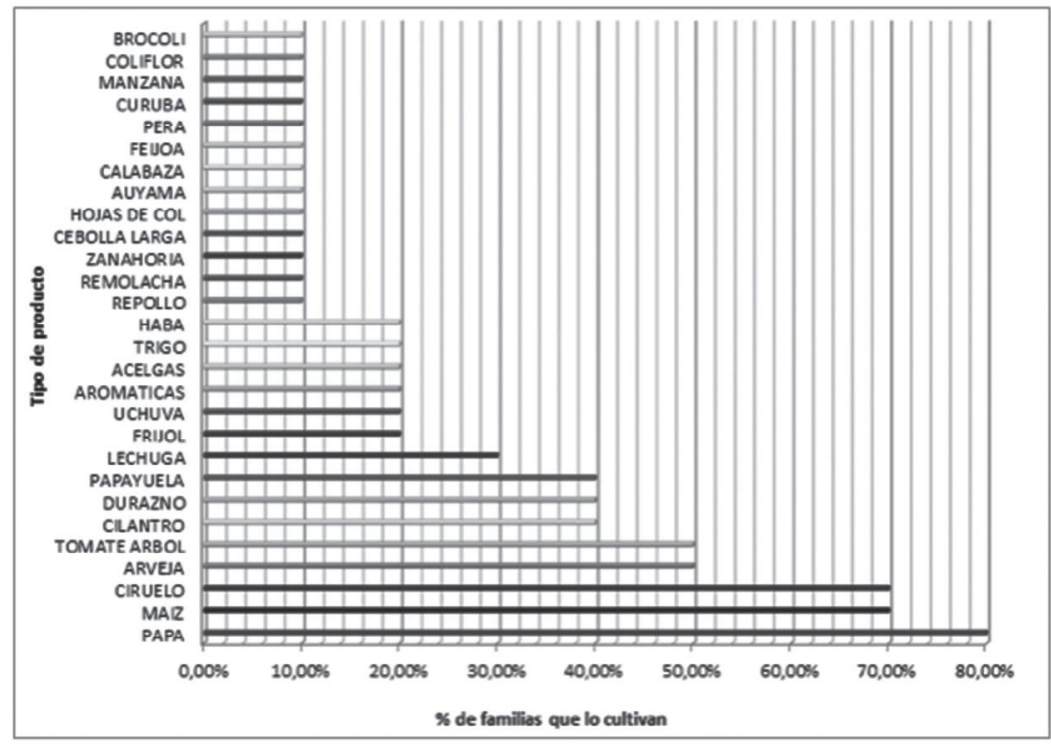

Figura 3. Productos agrícolas cultivados en las familias estudiadas

Fuente: autores, a partir de trabajo de campo 2011.

En estos sistemas agrícolas, la intervención de las mujeres ha venido aumentando en los últimos 10 años, según Farah (2004) ya que se evidencia la introducción de las mismas en la mayoría de las actividades como: adecuación de terrenos (45\% de las familias estudiadas), aplicación de abonos $(30 \%)$, siembra de semilla $(55 \%)$ cosecha (65\%) y venta de los productos agrícolas (40\%); actividades que antes eran exclusivas del género masculino (ver tabla 2).

Lo anterior se debe según conversaciones con las madres, a la escasa posibilidad de contratar mano de obra externa y a la poca extensión de los predios en donde los cultivos son pequeños y se hace necesaria la intervención de todos los miembros de la familia.

Tabla 2. Distribución de las labores agrícolas dentro del predio de las 10 familias más representativas

\begin{tabular}{|c|c|c|c|c|c|c|c|c|c|c|}
\hline & Familia 1 & Familia 2 & Familia 3 & Familia 4 & Familia 5 & Familia 6 & Familia 7 & Familia 8 & Familia 9 & Familia 10 \\
\hline \multicolumn{11}{|c|}{ SISTEMA AGRICOLA } \\
\hline $\begin{array}{l}\text { Adecua- } \\
\text { ción de } \\
\text { terreno }\end{array}$ & Hijo & Padre & Hijo & $\begin{array}{l}\text { Padre, } \\
\text { Hijo, Hija }\end{array}$ & $\begin{array}{l}\text { Padre, } \\
\text { Madre }\end{array}$ & Padre & $\begin{array}{l}\text { Padre, } \\
\text { Madre }\end{array}$ & Hijo, Hija & Padre & $\begin{array}{c}\text { Padre, } \\
\text { Hijo, } \\
\text { Abuelo }\end{array}$ \\
\hline $\begin{array}{l}\text { Aplicación } \\
\text { de Abonos }\end{array}$ & Hijo & Padre & Padre & $\begin{array}{l}\text { Padre, } \\
\text { Hijo }\end{array}$ & $\begin{array}{l}\text { Padre, } \\
\text { Madre }\end{array}$ & Padre & $\begin{array}{l}\text { Padre, } \\
\text { Madre }\end{array}$ & Hijo, Hija & Padre & $\begin{array}{c}\text { Padre, } \\
\text { Hijo, } \\
\text { Abuelo }\end{array}$ \\
\hline $\begin{array}{l}\text { Siembra } \\
\text { de semilla }\end{array}$ & Hijo & $\begin{array}{l}\text { Padre, } \\
\text { Hijo }\end{array}$ & $\begin{array}{l}\text { Padre, } \\
\text { Madre, } \\
\text { Hijo, Hija }\end{array}$ & Padre & $\begin{array}{l}\text { Padre, } \\
\text { Madre }\end{array}$ & $\begin{array}{l}\text { Padre, } \\
\text { Hijo }\end{array}$ & $\begin{array}{l}\text { Padre, } \\
\text { Madre }\end{array}$ & Hijo, Hija & Padre & $\begin{array}{l}\text { Padre, } \\
\text { Hijo, } \\
\text { Abuelo, } \\
\text { Madre }\end{array}$ \\
\hline Deshierbe & Hijo & Padre & Hijo & $\begin{array}{l}\text { Padre, } \\
\text { Hijo }\end{array}$ & $\begin{array}{l}\text { Padre, } \\
\text { Madre }\end{array}$ & Padre & $\begin{array}{l}\text { Padre, } \\
\text { Madre }\end{array}$ & Hijo, Hija & Padre & Abuelo \\
\hline Riego & $\begin{array}{l}\text { Hija, } \\
\text { Madre }\end{array}$ & $\begin{array}{l}\text { Padre, } \\
\text { Madre }\end{array}$ & $\mathrm{N} / \mathrm{A}$ & $N / A$ & $N / A$ & N/A & $N / A$ & $\mathrm{~N} / \mathrm{A}$ & $\mathrm{N} / \mathrm{A}$ & $N / A$ \\
\hline Cosecha & $\begin{array}{l}\text { Hijo, Hija, } \\
\text { Madre }\end{array}$ & Padre & $\begin{array}{l}\text { Padre, } \\
\text { Madre, } \\
\text { Hijo, Hija }\end{array}$ & $\begin{array}{l}\text { Padre, } \\
\text { Hijo }\end{array}$ & $\begin{array}{l}\text { Padre, } \\
\text { Madre }\end{array}$ & $\begin{array}{l}\text { Padre, } \\
\text { Hijo }\end{array}$ & $\begin{array}{l}\text { Padre, } \\
\text { Madre }\end{array}$ & Hijo, Hija & Padre & $\begin{array}{l}\text { Padre, } \\
\text { Abuelo, } \\
\text { Madre }\end{array}$ \\
\hline $\begin{array}{l}\text { Venta } \\
\text { productos }\end{array}$ & Hijo & $\begin{array}{c}\text { Padre, } \\
\text { Madre, } \\
\text { Hijo }\end{array}$ & Padre & Padre & Padre & $\begin{array}{l}\text { Padre, } \\
\text { Madre }\end{array}$ & Padre & $\begin{array}{c}\text { Hijo, Hija, } \\
\text { Madre }\end{array}$ & Padre & Madre \\
\hline
\end{tabular}

Convención: $\square$ Intervención Femenina. $\square$ Intervención Masculina. $\square$ Intervención mixta 
Además, ante la necesidad de que los hombres salgan a buscar jornales fuera del predio familiar hace que las mujeres que se quedan en el hogar, tengan que hacerse cargo de los cultivos pequeños en sus "ratos libres", disminuyendo drásticamente las posibilidades de descanso, multiplicando el trabajo de las mismas y aumentando las jornadas laborales.

Un punto importante a resaltar es la participación de los hijos (sobre todo los jóvenes ya sean hombres o mujeres) en las labores agrícolas, ya que en el $80 \%$ de las familias encuestadas estos deben ayudar con las labores productivas, pues su mano de obra es indispensable para el cultivo de productos destinados a la venta o al autoconsumo (ver Tabla 2).

En las familias donde el padre está ausente, las madres y los hijos (ya sean mujeres $u$ hombres) comparten las actividades agrícolas, siendo estos últimos los encargados de hacer las labores de fuerza (adecuación de terreno, deshierbe, etc.) y la madre la encargada de las labores de gestión (recolecta y venta de cosechas). Cuando los hijos son menores de 10 años, son tenidos en cuenta para actividades pequeñas (recolecta de hierbas, aromáticas, frutas del piso, entre otras), son actividades de ayuda, sin embargo, su participación en las labores agrícolas no es visible.

En cuanto a los sistemas pecuarios, estos se basan mayormente en la cría de aves y bovinos, ya que la cría de otros animales ha venido disminuyendo en los últimos 5 años (según diálogos con las madres) tal cual como se evidencia en las Figura 4. Las aves y conejos son destinados principalmente al autoconsumo, mientras que los bovinos, porcinos, caprinos y ovinos son destinados a la venta.
(A)

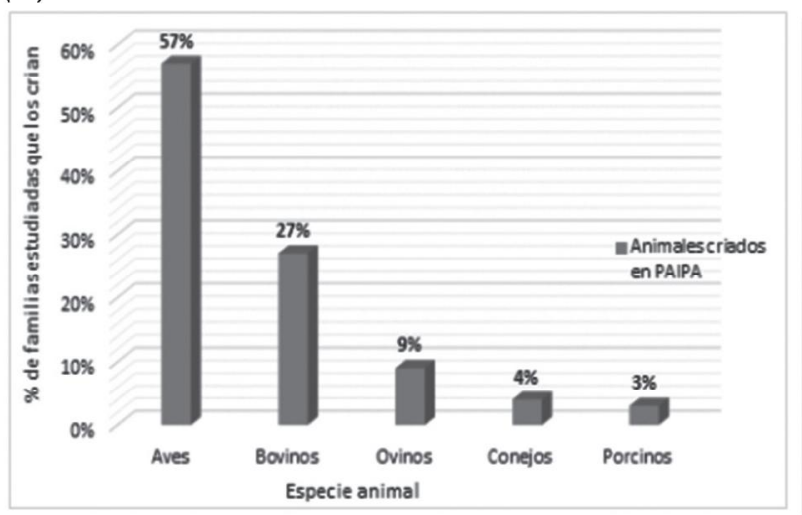

(B)

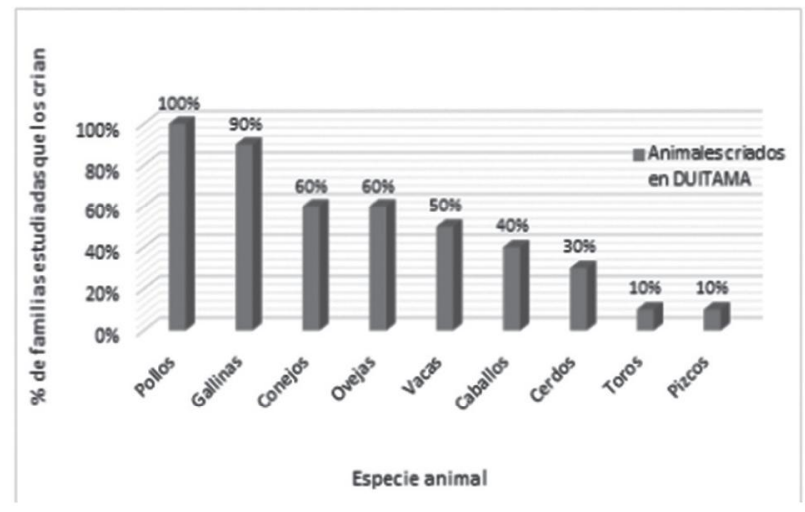

Figura 4. Especies criadas por las familias estudiadas de los municipios de Paipa (A) y Duitama (B)

Como se puede apreciar en la figura 4, las aves de corral son las que más se crían, debido a que son animales fáciles de cuidar, requieren pocos insumos y áreas de terreno dentro del predio, y producen huevos y carne como fuente de proteína primordial para la familia. No todas las familias crían conejos debido a que su consumo no es tan frecuente y en el mercado su demanda es baja comparada con la de otras carnes (res y pollo). Los demás animales se crían en menor proporción, debido a sus requerimientos nutricionales, necesidades de espacio dentro del predio y altos costos de producción. 
En las actividades de cría de especies menores (aves, conejos, ovinos caprinos y cerdos) la participación del padre es escasa, contrario a la cría de grandes especies como los bovinos, donde el padre o figura masculina adulta del hogar es quien realiza las actividades correspondientes a la adecuación de los potreros (cercado, bebedero, saladero) y algunas veces, el arreo (o traslado) de los animales, labor que últimamente está siendo desempeñada por las mujeres.
Indiscutiblemente, las mujeres juegan un papel fundamental en la permanencia y manejo de los animales en los predios (ver Tabla 3); en el $90 \%$ de las familias estudiadas son las encargadas de la compra, alimentación y manejo de los animales al igual que del aseo de las producciones con el apoyo de los demás miembros de la familia (hijos).

Tabla 3. Distribución de las labores pecuarias dentro del predio de las 10 familias más representativas

\begin{tabular}{|c|c|c|c|c|c|c|c|c|c|c|}
\hline & Familia 1 & Familia 2 & Familia 3 & Familia 4 & Familia 5 & Familia 6 & Familia 7 & Familia 8 & Familia 9 & Familia 10 \\
\hline \multicolumn{11}{|c|}{ SISTEMA PECUARIO } \\
\hline $\begin{array}{l}\text { Adecua } \\
\text { Potreros/ } \\
\text { Instalacio- } \\
\text { nes }\end{array}$ & Hijo & Madre & $\begin{array}{l}\text { Madre, } \\
\text { Padre }\end{array}$ & $\begin{array}{l}\text { Padre, } \\
\text { Hijos }\end{array}$ & $\begin{array}{l}\text { Madre, } \\
\text { Padre }\end{array}$ & Padre & $\begin{array}{l}\text { Madre, } \\
\text { Padre }\end{array}$ & $\underset{* * * \text { Hijos }}{\text { Hija, }}$ & Padre & Madre \\
\hline $\begin{array}{l}\text { Compra } \\
\text { animales }\end{array}$ & Madre & Madre & $\begin{array}{l}\text { Madre, } \\
\text { Padre }\end{array}$ & Madre & Padre & $\begin{array}{l}\text { Madre, } \\
\text { Padre }\end{array}$ & Padre & $\begin{array}{l}\text { Madre, } \\
\text { Hija }\end{array}$ & Madre & Madre, Hijos \\
\hline Alimenta. & Madre & $\begin{array}{l}\text { Madre, } \\
\text { Hija }\end{array}$ & $\begin{array}{l}\text { Madre, } \\
\text { Padre }\end{array}$ & Madre & Madre & $\begin{array}{l}\text { Madre, } \\
\text { Padre }\end{array}$ & Madre & $\begin{array}{l}\text { Madre, } \\
\text { Hija }\end{array}$ & Madre & Madre, Hijos \\
\hline Aseo & Madre & $\begin{array}{l}\text { Madre, } \\
\text { "Hijo }\end{array}$ & Madre & $\begin{array}{l}\text { Padre, } \\
\text { Hijos }\end{array}$ & $\begin{array}{l}\text { Madre, } \\
\text { Padre }\end{array}$ & $\begin{array}{l}\text { Madre, } \\
\text { Padre }\end{array}$ & $\begin{array}{l}\text { Madre, } \\
\text { Padre }\end{array}$ & $\begin{array}{l}\text { Madre, } \\
\text { Hija }\end{array}$ & Madre & Madre \\
\hline $\begin{array}{l}\text { Vacuna } \\
\text { /desparasita }\end{array}$ & $N / A$ & $\begin{array}{l}\text { Madre, } \\
\text { Padre }\end{array}$ & ${ }^{* *}$ Otros & $\mathrm{N} / \mathrm{A}$ & $\begin{array}{l}\text { Madre, } \\
{ }^{* \star} \text { Otros }\end{array}$ & N/A & $\begin{array}{l}\text { Madre, } \\
{ }^{*} \text { Otros }\end{array}$ & N/A & $N / A$ & N/A \\
\hline $\begin{array}{l}\text { Arreo } \\
\text { ganado }\end{array}$ & $N / A$ & Madre & Hijos & $\begin{array}{l}\text { Padre, } \\
\text { Madre, } \\
\text { Hijos }\end{array}$ & Madre & Padre & Madre & $\begin{array}{l}\text { Hija, } \\
\text { Nietos }\end{array}$ & Hija & Madre, Hijos \\
\hline $\begin{array}{l}\text { Recolecta } \\
\text { Productos }\end{array}$ & Madre & Madre & Madre & Hijas & $\begin{array}{l}\text { Madre, } \\
\text { Hijos }\end{array}$ & $\begin{array}{l}\text { Madre, } \\
\text { Padre }\end{array}$ & $\begin{array}{l}\text { Madre, } \\
\text { Hijos }\end{array}$ & N/A & Hija, Hijo & Hijos \\
\hline Ordeño & $N / A$ & $\begin{array}{l}\text { Madre, } \\
\text { Hija }\end{array}$ & Padre & $\mathrm{N} / \mathrm{A}$ & $\begin{array}{l}\text { Madre, } \\
\text { Hijos }\end{array}$ & $\begin{array}{l}\text { Madre, } \\
\text { Padre }\end{array}$ & $\begin{array}{l}\text { Madre, } \\
\text { Hijos }\end{array}$ & N/A & N/A & N/A \\
\hline $\begin{array}{l}\text { Procesa } \\
\text { Producto }\end{array}$ & Madre & N/A & $\mathrm{N} / \mathrm{A}$ & N/A & $\mathrm{N} / \mathrm{A}$ & $\mathrm{N} / \mathrm{A}$ & N/A & N/A & Madre & N/A \\
\hline $\begin{array}{l}\text { Venta } \\
\text { producto }\end{array}$ & Hija & Madre & $\begin{array}{l}\text { Madre, } \\
\text { Padre }\end{array}$ & Padre & Madre & Madre & Madre & $\mathrm{Hija}$ & Madre & Madre \\
\hline $\begin{array}{l}\text { Sacrificio } \\
\text { animales }\end{array}$ & Madre & $\begin{array}{l}\text { Madre } \\
\text { *Hijo }\end{array}$ & Madre & Madre & $\begin{array}{l}\text { Madre, } \\
\text { Padre }\end{array}$ & $\begin{array}{l}\text { Madre, } \\
\text { Padre }\end{array}$ & $\begin{array}{l}\text { Madre, } \\
\text { Padre }\end{array}$ & $\begin{array}{c}\text { Madre, } \\
\text { Hija }\end{array}$ & Madre & Madre \\
\hline
\end{tabular}

* Niño especial; ** Técnicos agropecuarios; ${ }^{* * *}$ Hijos que no viven en el predio. N/A: actividad no existente en la familia Convención: $\square$ Intervención Femenina. $\square$ Intervención Masculina. $\square$ Intervención mixta

En este sentido, las madres efectúan el ordeño, alimentación de los animales, preparación de productos (queso, cuajadas, kumis) y en algunos casos intercambio de productos como leche, huevos, verduras, por sal, panela, entre otros. Adicionalmente, las niñas, jóvenes y adolescentes (género femenino) ejercen en este ámbito productivo una labor de ayuda en todas las actividades descritas anteriormente, además de recolectar productos (huevos), asear los implementos de manejo (cantinas) y alimentación de los animales (sirven sal y agua al ganado, limpieza de bebederos y comederos).

\section{Rol de la mujer en la comercialización de los productos y labores extraprediales}

Las mujeres de las familias encuestadas han tenido una mayor participación en la venta de los productos cosechados en sus predios (frutales, verduras, leche, huevos, aves, quesos, lana, entre otros), ya que al dedicarse mayor tiempo a estas producciones han empezado a tener mayor poder de decisión y control sobre las mismas. 
Además, ellas han buscado diversos lugares donde pueden vender sus productos a mayor precio, ya que la mayoría de las mujeres entrevistadas (28 madres), reportaron que en las plazas de mercado locales el precio de los productos es muy bajo y no les pagan lo que en verdad pueden valer sus productos. Es así, que los productos se comercializan en diferentes lugares que van desde los vecinos y familiares, las tiendas de sus propias casas o municipales, hasta terminales de transporte, famas e intermediarios.

Los productos agrícolas como ciruelos y duraznos son vendidos por las mujeres en las terminales de transporte más cercanas; la arveja, la papayuela y el tomate de árbol son vendidos en la plaza de mercado local, otros productos pequeños son vendidos a los vecinos o en sus tiendas. Los demás productos agrícolas que se cultivan en mayor cantidad como la papa, maíz y la cebolla son vendidos por el padre cabeza de hogar o figura masculina de la familia (hijo mayor o hermano).

Sin embargo, aunque las mujeres son las que realizan la venta de los productos agrícolas, no siempre controlan el dinero obtenido de las mismas, ya que deben rendir cuentas al hombre cabeza de hogar cuando está presente; el porcentaje del dinero recolectado que deben entregar fue difícil de cuantificar, pues las mujeres encuestadas no facilitaron la información; no obstante, de los recursos monetarios recolectados de estas ventas entre el 70 y $80 \%$ debe ser entregado al jefe de hogar.

En cuanto a los productos derivados de la actividad pecuaria las mujeres tiene un mayor control sobre la venta y los recursos monetarios adquiridos; ellas son las encargadas de la venta de la leche, huevos y demás productos propios de especies como aves, conejos, caprinos, ovinos y cerdos. La leche es vendida a los vecinos, a la procesadora de leche de la vereda y al carro lechero; los pollos son vendidos a vecinos y familiares, en la plaza de mercado y en las tiendas de sus casas, y los huevos a los vecinos y tiendas de sus casas.
Los bovinos de engorde son vendidos por el hombre cabeza de hogar o figura masculina de la familia (hijo mayor o hermano) en las plazas de mercado locales y famas directamente de Paipa y Duitama.

En cuanto al control de los recursos monetarios obtenidos por la venta de los productos pecuarios, las mujeres tan solo entregan al hombre cabeza de hogar entre el 20 y el $30 \%$ de los recursos económicos recolectados, lo que significa que ellas pueden decidir y destinar la mayoría de dichos excedentes, los cuales casi siempre designan para comprar nuevos animales, reemplazar los vendidos y seguir con la producción pecuaria, compra de otros alimentos, ropa y artículos de aseo para su familia y gastos personales.

Por otra parte, las labores extraprediales fueron descritas previamente sin embargo, las mujeres madres las desarrollan con el fin de aumentar los ingresos monetarios pero no las destinan para sus propias necesidades (aseo personal, transporte, ropa, recreación, descanso, educación, entre otros) sino para complementar los recursos monetarios obtenidos por la familia y comprar alimentos y útiles necesarios para el hogar.

Las labores extraprediales desarrolladas por los hijos (jóvenes, adolescentes) son desarrolladas mayormente para suplir las necesidades económicas de ellos mismos (estudio, gastos de transporte, aseo, recreación, otros) y poco destinan para alimentación y demás gastos del hogar, los cuales deben ser asumidos por los padres.

\section{Rol de la mujer en el acceso y control de los recursos}

Como se ha descrito anteriormente, las mujeres de las familias estudiadas han tomado un papel verdaderamente participativo en el ámbito productivo de sus predios, lo que conlleva a que también tengan un verdadero acceso y control de los recursos (tierra, agua, alimentos, animales, dinero), ya que tienen todas las oportunidades de hacer uso 
de los mismos dentro de sus predios para satisfacer sus propias necesidades y las de su familia.

Adicionalmente, el poder decisivo de las mujeres dentro de sus predios ha ido aumentando con respecto al de los hombres, ya que sus decisiones son tomadas en cuenta por los mismos tanto en el sistema agrícola, pecuario y reproductivo, según como se puede apreciar en las Tablas 4, 5 y 6 y en conversaciones con las familias implicadas.

En el contexto reproductivo, las madres han empezado a tomar decisiones que son tenidas en cuenta por los jefes de hogar en cuanto a la distribución de los recursos económicos, educación de la familia (niños y jóvenes) y participación fuera de sus predios (ver Tabla 4).

Tabla 4. Toma de decisiones de las labores productivas y reproductivas dentro del predio de 10 familias representativas

\begin{tabular}{|c|c|c|c|c|c|c|c|c|c|c|}
\hline & Familia 1 & Familia 2 & Familia 3 & Familia 4 & Familia 5 & Familia 6 & Familia 7 & Familia 8 & Familia 9 & Familia 10 \\
\hline \multicolumn{11}{|c|}{ SISTEMA REPRODUCTIVO } \\
\hline $\begin{array}{l}\text { Educación de } \\
\text { la Familia }\end{array}$ & Madre & Madre & Padre & $\begin{array}{l}\text { Padre, } \\
\text { Madre }\end{array}$ & $\begin{array}{l}\text { Padre, } \\
\text { Madre }\end{array}$ & Madre & $\begin{array}{l}\text { Padre, } \\
\text { Madre }\end{array}$ & Hija & $\begin{array}{l}\text { Padre, } \\
\text { Madre }\end{array}$ & Madre \\
\hline $\begin{array}{l}\text { Organización } \\
\text { de la Vivienda }\end{array}$ & Madre & $\begin{array}{l}\text { Padre, } \\
\text { Madre }\end{array}$ & Madre & $\begin{array}{l}\text { Padre, } \\
\text { Madre }\end{array}$ & $\begin{array}{l}\text { Padre, } \\
\text { Madre }\end{array}$ & Madre & $\begin{array}{l}\text { Padre, } \\
\text { Madre }\end{array}$ & Hija & $\begin{array}{l}\text { Padre, } \\
\text { Madre }\end{array}$ & Madre \\
\hline $\begin{array}{l}\text { Salida a } \\
\text { Trabajar }\end{array}$ & Familia & Familia & $\begin{array}{l}\text { Padre, } \\
\text { Madre }\end{array}$ & Padre & Padre & Madre & Padre & & $\begin{array}{l}\text { Padre, } \\
\text { Madre }\end{array}$ & Padre \\
\hline $\begin{array}{l}\text { Dinero de } \\
\text { Alimentación }\end{array}$ & Madre & Padre & $\begin{array}{l}\text { Padre, } \\
\text { Madre }\end{array}$ & Padre & Padre & $\begin{array}{l}\text { Padre, } \\
\text { Madre }\end{array}$ & Padre & Familia & Madre & Padre \\
\hline $\begin{array}{l}\text { Dinero } \\
\text { Mobiliarios y } \\
\text { Utensilios }\end{array}$ & Familia & $\begin{array}{l}\text { Padre, } \\
\text { Madre }\end{array}$ & Madre & Padre & $\begin{array}{l}\text { Padre, } \\
\text { Madre }\end{array}$ & Madre & $\begin{array}{l}\text { Padre, } \\
\text { Madre }\end{array}$ & Familia & Madre & $\begin{array}{l}\text { Padre, } \\
\text { Abuelo }\end{array}$ \\
\hline $\begin{array}{l}\text { Dinero } \\
\text { Recreación }\end{array}$ & Familia & $\begin{array}{l}\text { Padre, } \\
\text { Madre }\end{array}$ & Madre & Padre & $\begin{array}{l}\text { Padre, } \\
\text { Madre }\end{array}$ & $\begin{array}{l}\text { Padre, } \\
\text { Madre }\end{array}$ & $\begin{array}{l}\text { Padre, } \\
\text { Madre }\end{array}$ & Familia & $\begin{array}{l}\text { Padre, } \\
\text { Madre }\end{array}$ & $\begin{array}{l}\text { Padre, } \\
\text { Abuelo }\end{array}$ \\
\hline $\begin{array}{l}\text { Participación } \\
\text { de Reuniones } \\
\text { Veredales }\end{array}$ & Familia & Madre & Padre & $\begin{array}{l}\text { Padre, } \\
\text { Madre }\end{array}$ & Padre & Madre & Padre & Madre & $\begin{array}{l}\text { Padre, } \\
\text { Madre }\end{array}$ & Abuelo \\
\hline
\end{tabular}

Convención: $\square$ Intervención Femenina. $\square$ Intervención Masculina. $\square$ Intervención mixta.

En lo que respecta a las producciones agrícolas, los hombres en su mayoría deciden la distribución del terreno y qué y cuándo sembrar, mientras que las mu- jeres deciden el destino de la producción y parte de las utilidades. En pocas familias (solo en 2 familias) estas decisiones se toman en conjunto (ver Tabla 5). 
Tabla 5. Toma de decisiones de las labores agrícolas dentro del predio de 10 familias representativas

\begin{tabular}{l|l|l|l|l|l|l|l|l|l|c|c|c|}
\hline & Familia 1 & Familia 2 & Familia 3 & Familia 4 & Familia 5 & Familia 6 & Familia 7 & Familia 8 & Familia 9 & Familia 10 \\
\hline $\begin{array}{l}\text { Distribución } \\
\text { de la tierra }\end{array}$ & Familia & Padre & Padre & Padre & Padre & Padre & Padre & Madre & $\begin{array}{c}\text { Padre, } \\
\text { Madre }\end{array}$ & $\begin{array}{c}\text { Padre, } \\
\text { Abuelo }\end{array}$ \\
\hline $\begin{array}{l}\text { Cultivos } \\
\text { a sembrar }\end{array}$ & Familia & Padre & Padre & Padre & Padre & $\begin{array}{l}\text { Padre, } \\
\text { Madre }\end{array}$ & Padre & Madre & $\begin{array}{c}\text { Padre, } \\
\text { Madre }\end{array}$ & $\begin{array}{c}\text { Padre, } \\
\text { Abuelo }\end{array}$ \\
\hline $\begin{array}{l}\text { Tipo y cantidad } \\
\text { de insumos }\end{array}$ & & Padre & Padre & Padre & Padre & $\begin{array}{l}\text { Padre, } \\
\text { Madre }\end{array}$ & Padre & Madre & Padre & $\begin{array}{c}\text { Padre, } \\
\text { Abuelo }\end{array}$ \\
\hline $\begin{array}{l}\text { Tecnologia } \\
\text { a utilizar }\end{array}$ & Familia & Padre & Padre & Familia & Padre & Padre & Padre & Familia & Padre & $\begin{array}{c}\text { Padre, } \\
\text { Abuelo }\end{array}$ \\
\hline $\begin{array}{l}\text { Destino de la } \\
\text { producción }\end{array}$ & Familia & Padre & Padre & Padre & $\begin{array}{l}\text { Padre, } \\
\text { Madre }\end{array}$ & $\begin{array}{l}\text { Padre, } \\
\text { Madre }\end{array}$ & $\begin{array}{l}\text { Padre, } \\
\text { Madre }\end{array}$ & Madre & Padre & $\begin{array}{c}\text { Padre, } \\
\text { Abuelo }\end{array}$ \\
\hline $\begin{array}{l}\text { Destino de } \\
\text { utilidades } \\
\text { Intercambio } \\
\text { de productos }\end{array}$ & & $\begin{array}{l}\text { Padre, } \\
\text { Madre }\end{array}$ & Madre & Padre & Madre & $\begin{array}{l}\text { Padre, } \\
\text { Madre }\end{array}$ & Madre & Familia & Padre & $\begin{array}{c}\text { Padre, } \\
\text { Abuelo }\end{array}$ \\
\hline
\end{tabular}

Convención: $\square$ Intervención Femenina. $\square$ Intervención Masculina. $\square$ Intervención mixta.

En cuanto a las producciones pecuarias, las mujeres tienen un gran poder decisivo dentro del predio; en la mayoría de las familias estudiadas ellas son las que resuelven qué especies y cómo se crían dentro de la unidad productiva; además, deciden sobre la venta de los productos y el destino de los ingresos. Esto se refleja mayormente en las especies pequeñas (aves, cerdos, conejos, ovinos y caprinos) como se evidencia en el análisis del sistema avícola en la Tabla 6.

Tabla 6. Toma de decisiones de las labores pecuarias dentro del predio de 10 familias representativas

\begin{tabular}{|c|c|c|c|c|c|c|c|c|c|c|}
\hline & Familia 1 & Familia 2 & Familia 3 & Familia 4 & Familia 5 & Familia 6 & Familia 7 & Familia 8 & Familia 9 & Familia 10 \\
\hline \multicolumn{11}{|c|}{ SISTEMA PECUARIO } \\
\hline $\begin{array}{l}\text { Animales } \\
\text { a Producir }\end{array}$ & Madre & Madre & Padre & Familia & Madre & $\begin{array}{l}\text { Padre, } \\
\text { Madre }\end{array}$ & Madre & Madre & $\begin{array}{l}\text { Padre, } \\
\text { Madre }\end{array}$ & $\begin{array}{l}\text { Padre, } \\
\text { Abuelo }\end{array}$ \\
\hline $\begin{array}{l}\text { Tipo y cantidad } \\
\text { de insumos }\end{array}$ & & Madre & Padre & Farnilia & $\begin{array}{l}\text { Padre, } \\
\text { Madre }\end{array}$ & $\begin{array}{l}\text { Padre, } \\
\text { Madre }\end{array}$ & $\begin{array}{l}\text { Padre, } \\
\text { Madre }\end{array}$ & Madre & Padre & $\begin{array}{l}\text { Padre, } \\
\text { Abuelo }\end{array}$ \\
\hline $\begin{array}{l}\text { Tecnología } \\
\text { a utilizar }\end{array}$ & Padre & Madre & Padre & Padre & $\begin{array}{l}\text { Padre, } \\
\text { Madre }\end{array}$ & $\begin{array}{l}\text { Padre, } \\
\text { Madre }\end{array}$ & $\begin{array}{l}\text { Padre, } \\
\text { Madre }\end{array}$ & Madre & Padre & $\begin{array}{l}\text { Padre, } \\
\text { Abuelo }\end{array}$ \\
\hline $\begin{array}{l}\text { Destino de la } \\
\text { producción }\end{array}$ & Madre & Padre & $\begin{array}{l}\text { Padre, } \\
\text { Madre }\end{array}$ & Madre & Madre & $\begin{array}{l}\text { Padre, } \\
\text { Madre }\end{array}$ & Madre & Familia & Madre & Abuelo \\
\hline $\begin{array}{l}\text { Destino do } \\
\text { utilidades }\end{array}$ & Madre & Padre & Padre & Madre & Madre & $\begin{array}{l}\text { Padro, } \\
\text { Madre }\end{array}$ & Madre & Familia & $\begin{array}{l}\text { Padro, } \\
\text { Madre }\end{array}$ & $\begin{array}{l}\text { Padro, } \\
\text { Abuelo }\end{array}$ \\
\hline $\begin{array}{l}\text { Intercambio } \\
\text { de productos }\end{array}$ & & & & & & $\begin{array}{l}\text { Padre, } \\
\text { Madre }\end{array}$ & & & Madre & \\
\hline \multicolumn{11}{|c|}{ PRODUCCIÓN AVICOLA } \\
\hline $\begin{array}{l}\text { Compra de } \\
\text { animales }\end{array}$ & Madre & Madre & Madre & Madre & $\begin{array}{l}\text { Padre, } \\
\text { Madre }\end{array}$ & $\begin{array}{l}\text { Padre, } \\
\text { Madre }\end{array}$ & $\begin{array}{l}\text { Padre, } \\
\text { Madre }\end{array}$ & Familia & Madre & Padre \\
\hline $\begin{array}{l}\text { Lugar y tipo de } \\
\text { instalaciones }\end{array}$ & Madre & Madre & Madre & Padre & Padre & $\begin{array}{l}\text { Padre, } \\
\text { Madre }\end{array}$ & Padre & Madre & $\begin{array}{l}\text { Padre, } \\
\text { Madre }\end{array}$ & $\begin{array}{l}\text { Padre, } \\
\text { Madre }\end{array}$ \\
\hline Alimentación & Madre & $\begin{array}{l}\text { Padre, } \\
\text { Madre }\end{array}$ & Madre & Madre & Madre & $\begin{array}{l}\text { Padre, } \\
\text { Madre }\end{array}$ & Madre & Familia & Madre & Padre \\
\hline $\begin{array}{l}\text { Manejo en } \\
\text { General }\end{array}$ & Madre & Madre & Madre & Madre & Madre & $\begin{array}{l}\text { Padre, } \\
\text { Madre }\end{array}$ & Madre & Familia & Madre & Madre \\
\hline $\begin{array}{l}\text { Venta de } \\
\text { Productos }\end{array}$ & Madre & Madre & Madre & $\begin{array}{l}\text { Padre, } \\
\text { Madre }\end{array}$ & Madre & $\begin{array}{l}\text { Padre, } \\
\text { Madre }\end{array}$ & Madre & Madre & Madre & $\begin{array}{l}\text { Padre, } \\
\text { Madre }\end{array}$ \\
\hline $\begin{array}{l}\text { Destino de } \\
\text { Ingresos }\end{array}$ & Madre & $\begin{array}{l}\text { Padre, } \\
\text { Madre }\end{array}$ & Madre & Madre & Madre & $\begin{array}{l}\text { Padre, } \\
\text { Madre }\end{array}$ & Madre & Madre & Madre & Padre \\
\hline
\end{tabular}

Convención: $\square$ Intervención Femenina. $\square$ Intervención Masculina. $\square$ Intervención mixta. 
Aunque en esta investigación no se estudió a fondo el contexto social - comunitario en el cual se desenvuelven las mujeres estudiadas, se pudo evidenciar que las mismas están empezando a tener control sobre las relaciones con su entorno, ya que desde hace 10 años, según Farah (2004), y según lo encontrado en esta investigación, se nota aún más el acompañamiento y/o asistencia de las mismas junto con sus esposos o género masculino a las reuniones veredales, de colegios de sus hijos y municipales (capacitaciones en la Alcaldía Municipal), entre otras (Tabla 4).

\section{Discusión y conclusiones}

Los anteriores resultados demuestran que el rol de la mujer en los contextos de los sistemas productivos ha ido cambiando en los últimos 20 años, ya que estudios como el de Pérez (1985), demuestran que en los años 80 la actividad principal de las mujeres en un $64.5 \%$ era el hogar, un $26.5 \%$ el estudio, sólo 2 mujeres reportaban la agricultura como su actividad principal y 3 la ganadería. Además, un estudio realizado en los años 90 por Farah (1996) evidencia que las mujeres ya tenían alguna participación en las labores agrícolas cuando ellas estaban en sistemas de producción con presencia de policultivos o donde el cultivo del tabaco era importante.

En este sentido, la mujer ha tenido que empoderarse de sus producciones y en los últimos 10 años del manejo de los recursos en general de sus predios. Este empoderamiento va direccionado al aumento de las actividades que debe realizar en su diario vivir y a las alternativas que ellas están utilizando para aliviarse de algunos trabajos (básicos del ámbito reproductivo) y poder hacerse cargo de otros (productivos y extraprediales) donde los hijos de todas las edades están involucrados.

Además, en el ámbito reproductivo de las familias estudiadas aunque las madres están buscando la ayuda de sus hijos para descargarse de dichas actividades, siguen estableciéndose situa- ciones de "jerarquías en el trabajo del hogar", lo que coincide con lo expuesto por Peredo citado en León (2003) quien explica que aunque todos ayudan con las labores reproductivas, la división del trabajo al interior de la familia reproduce la pirámide social en la que las mujeres ocupan la base, realizando las tareas más extenuantes y lo hacen con una mayor responsabilidad y vinculación identitaria.

Adicionalmente, las madres de las familias estudiadas siguen realizando las labores "gruesas" del hogar como cocinar, lavar la ropa de la mayoría de la familia, asear la mayor parte de la casa, velar por la cantidad y calidad de los alimentos entre otros; mientras que los hijos se hacen cargo ocasionalmente de arreglar sus cuartos, lavar su ropa, entre otras labores sencillas.

En cuanto al contexto productivo y más específicamente al agrícola, las mujeres (jóvenes, adolescentes y adultas) de las familias estudiadas han tenido que intervenir de forma activa para poder sacar adelante sus cultivos y tener cosechas para su consumo y venta; esta situación es repetitiva en la mayoría de los sistemas agrícolas campesinos a nivel nacional e internacional, ya que según Ballara, Damianovi \& Valenzuela (2012), quienes demuestran la relación entre la mujer y la agricultura en América Latina, afirman que en promedio el 78,5\% de las mujeres rurales, casi como patrón constante para la región, están incorporadas de manera activa al trabajo agrícola a partir de los 15 años de edad y hasta los 59 años, lo cual sucede en las familias estudiadas en donde el $80 \%$ de las mujeres están vinculadas.

En cuanto al contexto productivo pecuario, el que las mujeres de las familias estudiadas se hagan cargo de la mayoría de las actividades que conllevan estos sistemas, apoya lo que se ha venido afirmando en estudios de género como los de Farah (2003), Valderrama \& Mondragón (2008) y Giraldo (2008), en donde se ha demostrado que las mujeres son las que se encargan de las labores productivas de las especies menores y que en los 
últimos tiempos aportan ingresos económicos al hogar, debido a la venta de los productos obtenidos de los animales criados; no obstante, ahora las mujeres tienen más poder sobre los recursos económicos recolectados por estas producciones y pueden ejercer más control y autonomía sobre los mismos.

Lo anterior contradice lo expuesto por el PIDAASSA (2005), entidad que por medio de talleres desarrollados en algunas comunidades, ha descrito que el dinero que trae u obtiene el esposo es utilizado para gastos complementarios: ropa, educación, salud y vivienda, mientras que el ingreso por comercialización o trueque que realiza la esposa, es destinado para la alimentación familiar, por ello los ingresos de la comercialización que realiza la mujer, y su destino en el hogar es percibido como algo marginal, casi "invisible" y sin importancia.

En este sentido, las mujeres de las familias estudiadas de los municipios de Paipa y Duitama aportan verdaderamente a la economía de sus familias, ya que con estos ingresos suplen varias necesidades que no se solventan con el solo ingreso del padre cabeza de hogar, lo cual coincide con lo expuesto por Cervera et al. (1995, p. 85).

Otro aspecto importante a resaltar es la vinculación de las mujeres de las familias estudiadas al mercado, lo cual concuerda con lo descrito por Ospina (1998, p. 27), quien enfatiza que la distribución formal e informal de productos a través de ventas en los mercados locales, son manejados mayoritariamente por mujeres; sin embargo, conociendo que ellas todavía deben entregar cuentas (monetarias) a sus respectivos esposos y no se les valora en cierta manera el tiempo dedicado a su labor, sigue existiendo la llamada invisibilización del trabajo femenino, descrita por Ospina (1998, p. 26).

En este sentido, vale la pena resaltar que estas mujeres siguen teniendo un patrón de largas jornadas de trabajo, gracias a las múltiples actividades que los contextos productivos, reproductivos y extraprediales les exigen y aunque el tiempo que las mujeres dedican a cada una de ellas no fue cuantificado en este estudio, algunas cifras como las citadas por Ospina (1998, p. 30), describen que la jornada diaria de la mujer productora de alimento es de 13.6 horas o más, de las cuales el $54 \%$ lo destinan a las actividades domésticas y el restante $46 \%$ a actividades productivas, comunitarias y de estudio.

Hoy en día las jornadas pueden ser más largas, ya que las actividades extraprediales (tiendas dentro de sus casas, atender otras fincas, etc.) y de comercialización de sus productos hacen parte del día a día de las mujeres campesinas.

En definitiva, los roles de las mujeres campesinas estudiadas han sufrido un cambio en los últimos 10 años, en el sentido que ellas ahora hacen parte activa de sus sistemas productivos y económicos, tienen más acceso a los recursos de sus predios y ejercen más control y poder de decisión dentro de sus predios que 20 años atrás. Sin embargo, este empoderamiento tiene un gran precio: doblegar su carga laboral y trasferir algunas funciones básicas a sus hijos, los cuales solo estarán mientras cumplan edad para formar sus propios hogares y/o migrar a otros lugares.

Adicionalmente, ellas ahora hacen parte activa de las reuniones de las veredas, colegios, distritos de riego, entre otras, a las cuales muchos hombres por falta de tiempo (atender labores extraprediales) no pueden asistir.

Los cambios encontrados en los roles de las familias estudiadas reflejan la realidad de las mujeres campesinas de casi toda una región o un departamento; sin embargo, aunque los predios, reuniones, mercados y otros lugares estén llenos de mujeres campesinas, las leyes, programas y demás políticas públicas no tienen impreso de forma activa la cuantificación de su trabajo, la representación verdadera de su nuevo rol y menos la intervención de las mismas en el sostenimiento de sus familias. En pocas palabras, la remuneración efectiva por sus múltiples labores y esfuerzos cotidianos. 
Dicho de otra manera la invisibilización continúa, y las mujeres campesinas siguen "echándose al hombro" el doble de trabajo por algún peso extra.

Este escrito pretende hacer visible los cambios en el rol de la mujer y al mismo tiempo, el estancamiento de la sociedad y las políticas públicas ante los nuevos cambios campesinos. En este sentido, se hace necesario hacer más estudios en nuestra región que divisen y transmitan las actividades que las mujeres campesinas están realizando, y ayuden de cierta manera a presionar un cambio en el sentir y vivir de la sociedad hacia nuestros campesinos boyacenses.

\section{Literatura citada}

1. Abello, D. \& Blanco, V. (2007). La cestería en el municipio de Tenza, Boyacá, oficio tradicional de las mujeres. tesis de pregrado. (Licenciatura en Educación Básica con Énfasis en Ciencias Sociales). Universidad Pedagógica y Tecnológica de Colombia. Tunja. Colombia.

2. Ballara, M., Damianović, N. \& Valenzuela R. (2012). Mujer, agricultura y seguridad alimentaria: una mirada para el fortalecimiento de las políticas públicas en América Latina. En: ADDRESSING INEQUALITIES The Heart of the Post-2015 Development Agenda and the Future We Want for All Global Thematic Consultation. Recuperado de: http://www.marcelaballara.cl/genydes/2012\%20 Mujer,\%20agricultura\%20y\%20seguridad\%20alimentaria\%20Ballara\%20Damianovic\%20Valenzuel.pdf

3. Buitrago, L. \& Guerrero, J. (2009). De guerras y mujeres: La violencia en el Occidente de Boyacá, segunda guerra de las esmeraldas 1984-1990. tesís de pregrado. (Licenciatura en Ciencias Sociales). Universidad Pedagógica y Tecnológica de Colombia. Tunja. Colombia.

4. Farah, M. A. (1996). Equidad de género y sostenibilidad de sistemas de producción en el medio rural. Evidencias empíricas en la cuenca media del río Chicamocha. Boyacá, Colombia. Tesis de maestría en Desarrollo Rural). Pontificia Universidad Javeriana. Bogotá. Colombia.

5. Farah, M. A. \& Pérez, E. (2003). Mujeres rurales y nueva ruralidad en Colombia. Cuadernos de Desarrollo Rural. 51. p. 139. Pontificia Universidad Javeriana. Colombia.

6. Escorcia, H. S. (2005). Análisis y evaluación de una política pública que pretende la equidad de género: Estudio de caso: Consejo comunitario de mujeres departamental de Boyacá. (tesis de grado de pregrado en Ciencia Política). Pontifica Universidad Javeriana. Bogotá. Colombia.

7. Farah, M. A. (1996). Equidad de género y sostenibilidad de sistemas de producción en el medio rural evidencias empíricas en la cuenca del Rio Chicamocha-Boyacá. (tesis de grado Maestría en Desarrollo Rural). Pontifica Universidad Javeriana. Bogotá. Colombia.

8. Forero, J. (2003). Economía Campesina y Sistema Alimentario en Colombia: aportes para la discusión sobre seguridad alimentaria. Facultad de Estudios Ambientales y Rurales. Pontificia Universidad Javeriana. Bogotá.

9. Forero, E. G. (2003). Mujer rural y seguridad alimentaria estudio de caso en la vereda Guanegro del municipio de Puerto Boyacá. (tesis de grado pregrado Medicina Veterinaria y Zootecnia). Universidad Pedagógica y Tecnológica de Colombia. Tunja. Colombia.

10. Garzón, E., Palacio, M. \& Blanco, V. (2007). Estudio socio cultural y económico de la mujer campesina en el Municipio de Oicatá Boyacá. (tesis de grado pregrado Licenciatura en Ciencias Sociales). Universidad Pedagógica y Tecnológica de Colombia. Tunja. Colombia.

11. Giraldo, O. F. (2008). Seguridad alimentaria y producción pecuaria campesina: el caso de la localidad rural de Sumapaz. Revista Luna Azul. 27. p 49. Universidad de Caldas. Colombia.

12. IICA. (2000). Mujeres y equidad de género en la nueva visión de la ruralidad. Una propuesta del IICA para la acción estratégica. San José.

13. León, M. (2003). Mujeres y trabajo: cambios impostergables. 1‥ Ed. Veraz Comunicação, Porto Alegre, Brasil.

14. Pérez, E. (1985). Condiciones de producción y de los produtores de papa, maíz, tabaco y trigo en el norte de Boyacá: una experiencia de investigación participativa. Fundación San Isidro - Pontificia Universidad Javeriana. Bogotá. Colombia.

15. PIDAASSA. (2005) Programa de intercambio, dialogo, asesoría en agricultura sostenible y seguridad alimentaria. Taller de Diagnóstico de Comercialización Campesina e Inventario de Mejoras. Memorias. 09, 10 y 11 de agosto. Llata - Huanuco.

16. Rodríguez, R. \& Rodríguez, R. (1988). Participación de la mujer campesina en el trabajo familiar campesino en el municipio de Motavita (Boyacá). (tesis de grado pregrado Economía). Universidad Pedagógica y Tecnológica de Colombia. Tunja. Colombia.

17. Torres, N. F. (2004) Una evaluación de la participación local de las mujeres con perspectiva de genero en proyectos forestales municipales: El caso de "la Protección y Recuperación de la Microcuenca del Rio Monquira", municipio de Sogamoso (Boyacá). (tesis de grado Especialización Cooperación Internacional y Gestión de Proyectos para el Desarrollo). Universidad Externado de Colombia. Bogotá. Colombia.

18. Valderrama, M. \& Mondragón, H. (1998). Desarrollo y Equidad con Campesinos. Misión Rural. IICA. Volumen 2. Bogotá. Colombia.

19. Vera, Z. A. (1999) El desarrollo rural y la participación femenina: Estudio de caso Socotá - Boyacá. (tesis de grado Pregrado Veterinaria). Universidad Nacional de Colombia. Bogotá. Colombia.

20. Ospina, R. I. (1998). Para empoderar a las mujeres rurales. 1a . Ed. Bogotá. Colombia.

Recibido: 02 de abril de 2014 Aceptado: 06 de mayo de 2014 
